\title{
Modeling of Functional Dependence Emergent Qualities of Economic Systems
}

\author{
Larysa Lazebnyk \\ Department of Enterprise \\ Economics \\ University of the State Fiscal Service \\ of Ukraine \\ Irpin, Ukraine \\ 111808816@gmail.com \\ http://orcid.org/0000-0003-2234-4093 \\ Liudmyla Kravchenko \\ Department of Accounting, Audit and \\ Taxation \\ Khmelnytsky National University \\ Khmelnytsky, Ukraine \\ luda99@ukr.net \\ http://orcid.org/ 0000-0001-9903-649X
}

\author{
Nataliya Nykytchenko \\ Department of Commercial Law and \\ Procedure \\ University of the State Fiscal Service of \\ Ukraine \\ Irpin, Ukraine \\ revyuk@ukr.net \\ http://orcid.org/0000-0001-9545-1434
}

\author{
Viktoriya Hurochkina \\ Department of Enterprise \\ Economics \\ University of the State Fiscal Service \\ of Ukraine \\ Irpin, Ukraine \\ viktoriav2005@ukr.net \\ http://orcid.org/0000-0001-8869-0189
}

Abstract - Multilateral issues of ensuring prosperity country's economic system are the achievement of efficiency and success industrial enterprises in field behavioral aspect's entrepreneurship in emerging economy. Such a direction of research, which is leaked from experimental economy, places emphasis on strategic behavior of entrepreneurs operating in economy emergent type. Emergent responses and manifestations in global economy are both centralized and peripheral, which is also observed in Ukrainian economy. Therefore, for today remains the relevant direction of scientific research of characteristic signs of economic systems, namely new qualities which cannot be predicted, relying only on information concerning components of this system. Authors stewed key components of the emergence of an emerging economy on example of Ukraine that is concentrated in Financial, Social, Management and Innovation blocks. It characterized manifestations of emergence properties and it specified priority directions of development an economic system. Interconnection of innovations and emergence economic system is revealed that concentrates attention to the level of implementation emergent qualities of economic system that is characterized on ratio (relation) of innovation activity to the emergence. Article proposes a scientific and methodical approach to construction an economic model functioning of industrial enterprises, their mergers, unions and / or types their economic activity in conditions an emergence economy, which elements of system and their functional dependence are specified, stages formation emergent economic system are indicated.

Keywords - emergence economics, economy emergence type, economic security, industrial enterprises, economic modeling

\section{INTRODUCTION}

The challenges of transformational change and transformation are related to the turbulence of the economic system. Investigating processes of turbulence, it should be noted that they have characteristic signs of the stabilizing and destabilizing factors that it is impossible to predict, relying only on information concerning components of an economic system. The stabilizing factors have positive characteristics that are shown by synergy and emergence manifestations. Estimations of their level and ponder ability of influence on effectiveness of functioning sub maintaining an economic system it is inseparably linked with definition of factors of influence and cause-effect relationships which are a basis of modeling of processes in economy with emergence properties.

The methodology of determination emergence qualities and characteristics of an economic system is put in researches of behavioral and experimental economy. The methodology of experimental economy causes carrying out the controlled experiments having joint lines. To kinds of experiments belong: Imitation and modeling of dynamic processes; formations of an economic system under influence of the experimenter, and economic agents act the individuals who are picked up according to criteria of the experimenter.

The behavioral economy considers not realness of psychological prerequisites which change neoclassical models. It is based on the base of psychology (in which "loop" is a complex of behavioral mistakes and anomalies is inherent) and formations of strategy subject depending on strategic decisions of participants market relations.

The methodology of research theory economy emergence type provides studying strategic interactions subjects maintaining an economic system at which there is not predicted effect(s) is useful. Strategic interaction subjects maintaining an economic system lies in plane of researches experimental and behavioral economies.

For this reason for research of emergence properties an economic system it is necessary to define key components of formation emergence economies for the purpose of further creation economic model of functioning industrial enterprises, merge that about "a unification enterprises and/or types of their economic activity. It will allow defining profitability, system effect of an emergence and integrity structure an economic system. 


\section{LITERATURE REVIEW}

The hypothesis of a phenomenon "emergence" institutional an order for economy was defined by Adam Smith. Behind this idea it is defined that the truth opens in the form of sense that is embodied in rules and traditions which were created inexplicable way in an extreme antiquity thanks to social interactions of individuals. Such interpretation belongs allocation of the behavioral aspect given treatments. Such interpretation of emergence properties of an economic system belongs to behavioral aspect of interpretation of this concept. That is it social interaction of assumed there can be new qualities of a system which change characteristics of the last. However, for designation like an economic system as "emergence" in 1981 p. Antoine W. Van Agtmael introduced into the economic dialect "emergence" та "emerging markets" when worked in International Finance Corporation (IFC). He hoped to create what he had named: a set of promising stockmarkets, lifted from obscurity, thereby attracting the investment they needed to thrive.

Therefore, the term "emergence" call such type of economic systems for which is characteristic emergence of new qualities which cannot be predicted, relying only on information concerning components of this system. Emergence effect in an economic system it is the simplest to explain achievements with coordinated group activity. Therefore, behavioral economy is cornerstone studying of emergence properties economic systems. Researches of behavioral and experimental economy are thoroughly covered collection of scientific works Behavioral and Experimental Economics under the editorial office Steven N. Durlauf, Lawrence E. Blume in which it is in details described theoretical and methodological bases by leading practicals in this direction of scientific research [1].

Paradox Ellsberg (Allais) and alternative concept of decision-making in conditions of uncertainty "theory of prospects" was cornerstone formation behavioral economy. So, J. fon Neumann and A. Morgenstern in the monograph "Game Theory and Economic Behavior" opened a new way of assessment usefulness - theory expected (expected usefulness). The Nobel Prize laureate on economy of 1988 Maurice Allais noted that individual who behaves rationally prefers not behavior of expected usefulness aimed at receiving maximum, but behavior of achievement absolute to reliability, as received name "Allais's paradox".

J. Reynolds noted that emergence the state of the economy has colonial origins as has sources from capitalist expansion. Such practice in present neoliberal policy causes manifestations emergence conditions of an economic system. Major factors of influence on manifestations' emergence characteristics of economy he recognized first, cause and effect causal relationships between capitalism and an imperialism, secondly, function of management safety of national economy and its dependence on influence external financial crises [2]

Emergence economy and emergence manifestations in activity of economic systems remain today relevant an actual object of scientific knowledge. They take place in newly Emerging industry that are formed including under the influence of new digital technologies (which are an example of emergence manifestations) and can create the newest, progressive economies of the world, for example: India and China.

In works "Strategic Research of the Crossing of the "Death Valley" in Newly-Emerging Industry" Jinsong Gou, Jinyu Li, Pingnan Ruan is considered to study the formation newly-emerging industry on the basis of philosophy. Based on the four-dimensional perspective of "science-technologyengineering-industry", the paper follows the general law of the growth of newly-emerging industry to discuss its connotation, growth phases, technology innovation in different stages, and traits of market needs [3].

S. Sadare in the work "Short Run Economic Impact of Disruptive Technologies in Emerging Economies" considered influence of technology factors on development of country, for example India. Technological innovations of author carried new digital technologies: Mobility, Cloud, Big Data, Analytics, Robotics and Internet. It noted that there are highlights some short run economic fallout due to digital technology disruption especially in emerging economies [4].

Hana Esmail, Nedra Shili in their scientific work "Key Factors of China's Economic Emergence" have spent an empirical study that follows the Ordinary Least Square Method (OLS) as an analytical method between determined variable by using multi regression equation. The structural policies and the reforms adopted in agriculture, industry, trade and financial sector were favorable to China's economy and made of it an economic power in terms of real economy as proved favorable by the annual growth of its GDP [5]

In 2011 the international community allocated an emergence for World Economic Forum characteristic of development an economic system that arises thanks to a combination technological, standard and business factors of technological, regulatory and business factors are personal data in the context of reliability assurance at use and storage of their authenticated appearance. «Decades-old privacy laws and policies could not have foreseen the emergence of digital personal data as a valuable asset. Inadequate legislation has thus made standards surrounding the use of personal data inconsistent» [6]. Nowadays current asset inflates (databases) of a cost type and has standard legal support for processing of personal data.

Ukrainian scientists recognize existence of emergence manifestations in national economy and cluster economic systems too. So, M. Voynarenko, K. Dumanska and N. Ponomaryova thoroughly investigated the processes of formation of company's economic activity context in the strategic positioning process in emergent environment condition [7]. Author of an article "Justification Of Effective Choice Of Strategic Position" is provided by the concept of formation of company's economic activity context in emergent environment. And to note key problems of strengthening of company's strategic position in conditions of changeable economic environment with undefined factors, which can be solved with the help can be solved by means of the developed model of company's economic activity context on the basis of methods of mathematical modeling. 
Modeling of processes of adoption management decisions in conditions of variability to uncertainty and multidimensional market environment on formation elements security system of enterprise is offered in scientific work by P. Hryhoruk et.al [8].

L. Lazebnik researched reserves of improving competitiveness in national economy emergence type and offered financial and integration mechanisms of development an economic system. In scientific work "Reserves Of Improving Competitiveness Economy Emergence Type" grounded the tesis that in Ukraine political actions will have an effect on economic development and competitiveness increasing in case of their accordance to those form of enterprise, which are approved by an east culture [9].

L. Karpenko, P. Voronzhak in the article "Statement of Budgeting Management at Industrial Enterprises in Coordinates of the Financial and Economic Security System" paid attention to significant influence of the budgetary management to development of the industrial enterprises. Still authors noted that strategy of activation of innovative and investment development is a part of the strategic development of the entire process of industrial enterprise development [10]. Researches of emergence qualities and major factors influence on development of economic system is relevant and takes significant place in scientific knowledge.

\section{CONCEPTUAL BASIS OF FUNCTIONAL DEPENDENCE OF} EMERGENCE CHARACTERISTICS OF AN ECONOMIC SYSTEM

Emergent (from lat. Emergo - appear, arise, engl. emergence - the emergence of new) system properties qualitatively new properties that can not be predicted, based on the sum of components of the system [11]. Emergent as an object of a political economic study is a relationship between economic entities in the conditions of the emergence and accumulation of quantitative and qualitative innovations in the elements of the system, which generate a multivariate development of the economic situation and complicate economic entities and regulatory structures optimization of their target function [9]. The term "emergent economies" and "emergencies" are used to determine the type of economic system of "emerging", "new", "having potential for development", with changes taking place under the influence of the phenomena that trigger these progressive changes and innovations. The study of the motivating changes is inextricably linked with the study of the conditions of stabilization and ensuring absolute reliability in making managerial decisions.

Currently, the "emergency" and "emergency economy", which means the state of emergency, means a high risk and volatile environment, is in the scientific circle. Prevention of this type of emergent economy has a normative and legal interpretation, for example, National Emergencies Act of the United States.

In our opinion, "emergent economy" and "emergence economy" have a causal relationship - first creates the preconditions for the second, that is, an innovative leap occurs after the crisis in an unstable environment.

New qualities of an economic system form the new industries, creating a new stage of evolution industry. So,
Jinsong Gou, Jinyu Li, Pingnan Ruan have experienced that "In recent years, scholars have begun national-level discussions about issues in the development of newlyemerging industry, but it is still insufficient in relation to the awareness of the fundamental laws in emerging industry evolution, such as connotation of emerging industries, its essential characteristics and constraints"[3]. Internal factors and features of modern conditions managing is the dependence of success industrial enterprises not only on strategic potential, and on strategic decisions of other participants market relations. External factors influence are emergence characteristic signs which sources begin with the current debt and financial crises of capitalism that as a result generate emergence responses of world economy.

Since 2011, financial markets of euro zone were characterized by turbulent situation. According to the European bank (EBA) among maidens "From 90 banks eight suffered failures, without having passed stress tests. Among them 5 banks of Spain, 2 banks of Greece and 1 bank of Austria were in critical condition and became bankrupt. One more bank Helaba, Germany came nearer to such situation. Besides, 16 were in an approximate state to threshold values of bankruptcy according to EBA. The cumulative deficiency of the capital was 2.5 billion euros. It induced to extraordinary convocation of summit leaders in member countries of European Union in settlement of adverse calls and emergence manifestations of economy for strengthening economic - financial safety of the Eurozone.”

The instability was observed in the United States, however for last 5-6 years gradually financial conditions began to improve. So in 2017, world financial volatility decreased considerably and restored availability to the international bank credits. Good results of improvement are observed in stock markets. Investors show interest not only to the developed countries, and to developing countries. However in 2018 negative symptoms are observed again and considerable level of unstable manifestations in the developing economies amplifies. Such trend has dual character as it can affect as it is positive, so I is negative on development international economic interactions and on development of countries.

H. Shabib in article "Pakistan: from Emerging to Emergency Economy" noted that Pakistan - an economy so rich in every kind of resource is made to succumb mainly because of those who are at the helm of decision making. Apart from others, factors like energy and power crisis, depreciation of rupee, increasing burden of foreign debt and the adverse impact of growing cross-borders smuggling into Pakistan, spotted as the key aspects responsible for the misfortune of potentially emerging economy [13].

Adverse calls and threats to national security of euro zone have a considerable impact on economy of Ukraine. Strengthening of influence took place after euro integration choice of our country. Financial food of the Ukrainian economy depending on the International Monetary Fund and other financial institutions. Besides, condition of turbulence national economy amplifies military aggression of the Russia (annexation Crimea and anti-terrorist operation in the east of country). For this reason considering an emergence economy of Ukraine, it is necessary to begin on 
identification regularities and trends of functioning industrial enterprises and interconnection components and conditions of effective interaction and characteristic types and their parameters re connections in system of their managing as one of internal prerequisites of sudden appearance of emergence manifestations and calls. It is important to evaluate the components and conditions of effective interaction and characteristic indicators and their parameters. The main components of formation emergence economics is formation in country of following blocks that change under the influence of information technologies for reliability assurance, namely: financial, social, administrative, innovative (Fig.1).

In Ukraine, it is already introduced financial, social, the first steps on administrative the block of changes is taken, however for achievement of development innovative block there is considerable a number steps on their realization. On condition of introduction and effective realization of specified component's achievement of creative economy is possible. It has to not only financial and material value, and cultural. On the principles of creative economy transfer knowledge to all sectors economy is carried out and is an important component for inclusive development of the country.

For formation of emergence qualities an economic system, it is necessary to characterize major factors of influence that induce to gain the system of new qualities and generate potential to development - it is innovations and violation of reliability and risk-taking for environment. And acts of terrorism (in world economy) and raider attacks (in national economies) are external factors of influence on emergence manifestations in economy and in functioning of the industrial enterprises financial, currency, exchange crisis. Today situation with raider practicians in Ukraine is fed with military aggression. Therefore, considering an emergence economy, to main place there is a condition of national security of Ukraine. It forms the environment of functioning industrial enterprises and behavioral aspects of leading persons in adoption management decisions.

The internal factors influencing the functioning of industrial enterprises under the conditions of an emerging economy are the levels of development of economic potential and creative behavior. As for the first component, it should be noted that it covers such important indicators of the company as: energy security, material and financial security, access to cheap credit resources, competitiveness (enterprises and products), intellectual development, innovation, level of social security and employee motivation, environmentally friendly production products, import dependence, technological equipment and availability of technologies, informatization cuber security.

The methodology research of theory economy emergence type provides studying of creative competitive environment behavior. That is studying processes formation new ideas in competitive environment, and an innovation are result of introduction creative economy. Economic modeling emergence economy consists in formation in economic mathematical plane of accounting factors influence on a system and results of its functioning. Macro function is quantitative expression of a main objective system, depends on the cost resources which it consumes.
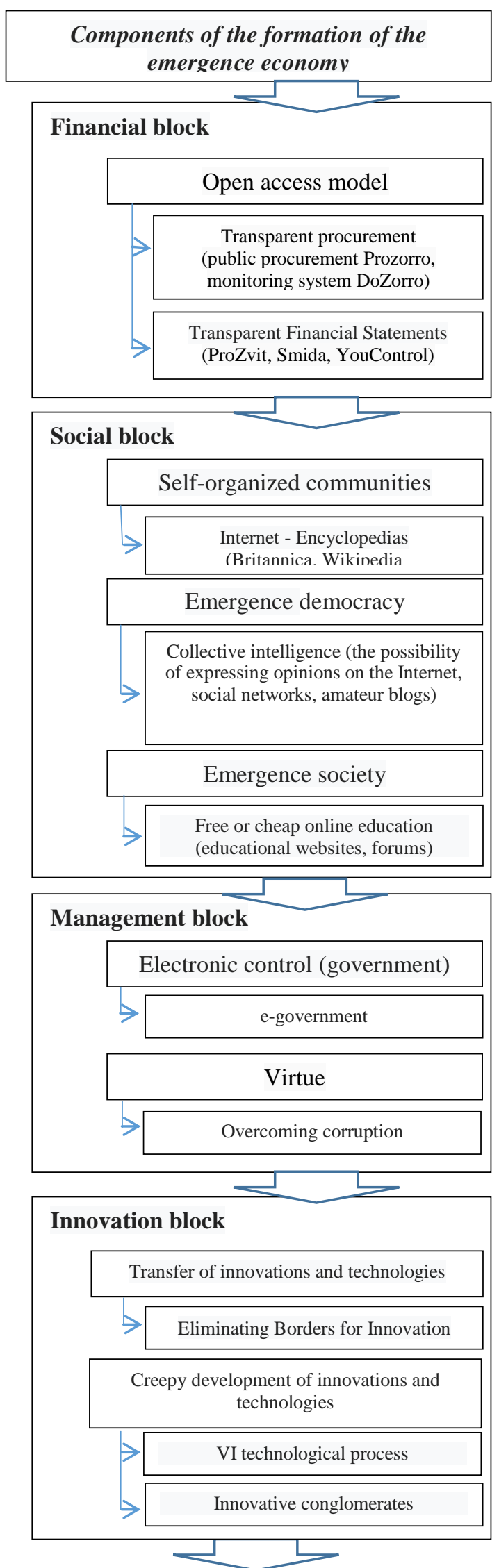

Prerequisites for a creative economy

Fig. 1. Components of the emergence of an Emerging economy. 
The choice of macro function provides achievement of necessary value cost efficiency of a system managing enterprises and linked with the solution tasks facing a system. Only in the presence of certain resources $\left(U_{o}\right)$ perhaps ensuring efficiency $\left(E_{o}\right)$ of a system. Mathematical expression macro function has an appearance [11]:

$$
F: U_{o} \longrightarrow E_{o},
$$

Achievements of a main objective system it is possible at realization macro function $(\mathrm{F})$, which there has to correspond a certain structure of a system (G) and its integrity or emergence $(R)[11]$

$$
R: F \longrightarrow G,
$$

Consequently, the effect of the emergence $(\mathrm{R})$ on the macro function of the system $(\mathrm{F})$ determines the optimality of the structure $(\mathrm{G})$ it implements. Under conditions when the correspondence between the macrostructure and the structure changes, there is an emergence (R).

Therefore, influence of an emergence (R) on macro function sets systems $(\mathrm{F})$ optimally to structure $(\mathrm{G})$ which it realizes. In conditions when compliance between macro function changes and structure, the relation of emergence is broken (R).

However, it is necessary to pay attention to what according to "a paradox" the individual who behaves rationally prefers to Allais not behavior of obtaining the maximum expected usefulness, but behavior of achievement of absolute reliability. Therefore, it is necessary to revise functional dependence of an emergence (2) through a prism of economic reliability or safety.

In that case, changes macro function systems $(\mathrm{F})$ under the influence of the level of economic security (ES) that affects further structure $(\mathrm{G})$ and its additivity (A) or emergence (R). Level of economic security induces an economic system to transformational changes and an innovation, in it and innovative function of risk is shown.

The following conditions must be fulfilled with:

1. The higher level of economic security (ES), the more balanced structure of economic system $(\mathrm{G})$ (become a structure).

$$
E S \uparrow=\text { const } G
$$

2. The higher level of economic security $(E S)$, the more additive property of the economic system and the linearity of the connection between its elements, that is, the emergence $(\mathrm{R})$ has a minimal value.

$$
\left\{\begin{array}{l}
E S \longrightarrow \max , \\
R \longrightarrow \min ,
\end{array}\right.
$$

3. The level of economic security has an effect on $\mathrm{x}$ the value of the emergence $(R)$.

$$
\uparrow E S \stackrel{x}{\longrightarrow} \downarrow R
$$

Under the conditions of increasing the riskiness of the environment and reducing the level of economic security, the potential opportunities of industrial enterprises are accumulated, and there is a manifestation of nonlinear increase of imperceptible properties, unpredictable bifurcation of elements of the system and recombination of interfunctional connections.

Therefore, the interconnection of innovation and the emergence of an economic system can be constructed as follows:

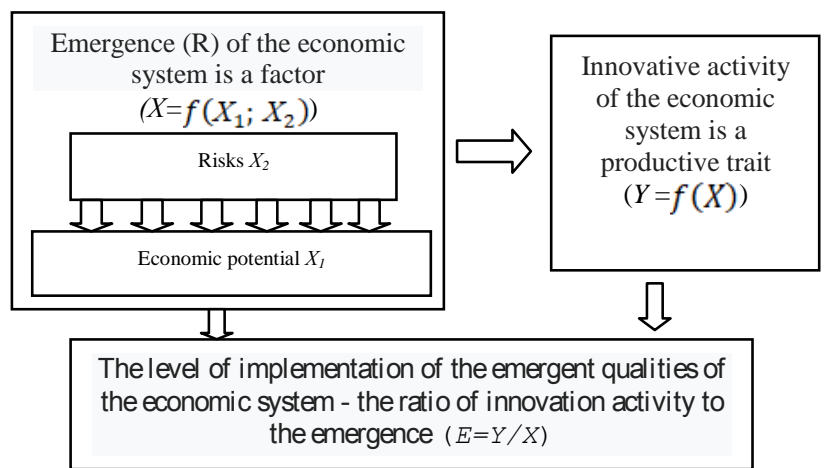

Fig. 2. Interconnection of innovations and the emergence of the economic system.

Therefore, considering the aforesaid we will construct economic model of functioning of the industrial enterprises, their merges that about a unification of the enterprises and/or types of their economic activity in conditions emergence economies will be the following:

$$
\left\{\begin{array}{l}
P=Q-I-C^{t}-C^{l}-C^{p}, \\
S^{e}=C^{r} \cdot\left(\sum_{i=1}^{n} V_{r c i}+\sum_{j=1}^{n} V_{b p_{j}}+\sum_{\kappa=1}^{n} V_{c}\right), \\
S=\left\langle C_{s m}, E(P), F, G, R, S^{e}\right\rangle
\end{array}\right.
$$

where $P$ - profit of an industrial enterprise, UAH (currency); $Q$ - proceeds from sales, products, goods and services, UAH (currency); I - investment value of the merger and merger enterprises and / or types their economic activity, UAH (currency); $C^{t}-$ tax expense, UAH (currency).; $C^{l}-$ logistics costs (transport), UAH (currency); $C^{p}-$ cost of production, goods and services, UAH (currency);

$S^{e}$ - systemic effect of the emergence from mergers and combinations of enterprises and / or types of their economic activity, UAH.; $K^{r}$ - coefficient of emergence, which reflects the quantitative assessment of qualitative synergistic effects in the economic system, UAH.; $V_{r c i}$ - the value of economic relations with the consumer, $\mathrm{UAH} ; V_{b p_{j}}$ - value of business processes with the supplier and / or the intermediary, UAH; $V_{c}$ - capitalization of business combinations and / or financial expenses of their economic activity, $\mathrm{UAH}$;

$\mathrm{S}$ - economic system; $U_{s}$ - cost of resources of the system of management of industrial enterprises, UAH; $E(P)$ economic efficiency of the system, profit, UAH; $F$ - macrofunction of the economic system; EU - level of economic 
security, $\% ; R$ - emergence, $\% ; G$ - structure of the economic system.

The offered dependence assumes identification of key factors. At estimation of level economic security external and internal factors of influence on functioning industrial enterprises are considered. Also it is necessary to isolate that in course of adoption management decision except the choice criterion of reliability, remain major factors of influence on development emergence qualities industrial enterprises: market potential, availability of innovations and information, state of environment, availability of resources and stable political situation.

\section{CONCLUSIONS}

As a result of the research, an economic model of the functioning of industrial enterprises, mergers and combinations of enterprises and / or types of their economic activity in the conditions of an emerging economy was developed, in which indicators of such subsystems were calculated, such as the profitability of enterprises, the systemic effect of the emergence, the impact of economic security on the integrity structure and functional dependence of the endangered characteristics of the economic system. In the future, this will enable to form and describe the most characteristic features for subsystems and their interconnections.

Authors it is offered and substantiated a conceptual basis of functional dependence of emergence characteristics of economic system and that it is focused on definition of influence level of economic security and an economic system (the industrial enterprise) on emergence qualities that are set by compliance stability and balance structure of an economic system (the industrial enterprise).

The offered dependence assumes studying of key factors influence on economic security and in execution macro function systems. Such approach estimation of emergence qualities an economic system outlines limits of function and set type economic growth to a system.

\section{ACKNOWLEDGMENT}

The work was carried out within research work on the subject "Ensuring Economic Security of the Enterprises in the conditions of Globalization" (the state registration number №0114U006380) 2013-2018 years.

\section{REFERENCES}

1] S. N. Durlauf, and L. E. Blume, "Behavioural and Experimenta Economics", Palgrave Macmillan Publishers Ltd, London, 2010. [Online]. Available: https://link.springer.com/book/10.1057\% 2F9780230280786 Accessed on: July 5, 2019.

[2] J. Reynolds, "The Political Economy of States of Emergency" 14 Oregon Review of International Law vol.14(1), 2012. [Online]. Available:https://papers.ssrn.com/sol3/papers.cfm?abstract_id=21735 35 Accessed on: July 5, 2019.

[3] J. Gou, J. Li, and P. Ruan, "Strategic Research of the Crossing of the "Death Valley" in Newly-Emerging Industry", International Conference on Advances in Social Science, Humanities, and Management, pp. 719-725, 2013. Doi: https://doi.org/10.2991/asshm13.2013 .134

[4] S. Sadare, "Short Run Economic Impact of Disruptive Technologies in Emerging Economies", International Conference on Communication and Signal Processing, Advances in Intelligent
Systems Research, Vol. 137, pp.793-797, 2016. Doi: https://doi.org/10.2991/iccasp-16.2017.107

[5] H. Esmail, and N. Shili, "Key Factors of China's Economic Emergence", Mediterranean Journal of Social Sciences, 2017. [Online].

Available: https://www.researchgate.net/publication/316900681_Key_Factors_of China's_Economic Emergence Accessed on: July 6, 2019.

[6] Personal Data: The Emergence of a New Asset Class. An Initiative of the World Economic Forum January 2011 In Collaboration with Bain \& Company, Inc. [Online]. Available: http://www3.weforum.org/docs/WEF_ITTC_PersonalDataNewAsset_ Report_2011.pdf Accessed on: July 10, 2019.

[7] M. Voynarenko, K. Dumanska, and N. Ponomaryova, "Formation of company's economic activity context in the strategic positioning process in emergent environment conditions", The 8th International Conference on Monitoring, Modeling \& Management of Emergent Economy, vol. 65, pp.1-7, 2019, Doi: https://doi.org/10.1051/shsconf/20196504005.

[8] P. M. Hryhoruk, N. A. Khrushch, and S. S. Grygoruk, "An approach to construct fuzzy preference relationships for managerial decision making", Scientific bulletin of Polissya, vol.4(12), no.2, pp.92-99, 2017. Doi: 10.25140/2410-9576-2017-2-4(12)-92-99

[9] L. Lazebnyk, "Reserve the competitiveness of the economics of the emergent type", Theoretical and Applied Economics Issues, 2012, [Online].Available:http://nbuv.gov.ua/UJRN/Tppe_2012_27\%282\%2 $9 \_7$ Accessed on: July 8, 2019.

[10] L. Karpenko, and P.Voronzhak, "Statement of Budgeting Management at Industrial Enterprises in Coordinates of the Financial and Economic Security System", International Relations 2017, Current issues of world economy and politics: Conference proceedings 18th International Scientific Conference Smolenice Castle, Bratislava, 2017, [Online]. Available: https://fmv.euba.sk/www write/files/aktuality/2018/International Rel ations_2017_Current_issues_of_world_economy_and_politics.pdf Accessed on: July 9, 2019.

[11] Emergence. [Online]. Available: https://en.wikipedia.org/wiki/Emergence

[12] I. A. Senenko, "Economic model of the hotel business management system", Effective economy, vol.4, 2017, [Online]. Available: http://www.economy.nayka.com.ua/?op=1\&z=5538 Accessed on: July 7, 2019.

[13] H. Shabib, "Pakistan: from Emerging to Emergency Economy!!!", International Journal of Humanities and Social Sciences (IJHSS), 2012, [Online]. Available: https://www.researchgate.net/publication/261360503 Accessed on: July 7, 2019.

[14] V Quadrini, "The Growth of Emerging Economies and Global Macroeconomic Stability", Working Paper, 2018. [Online]. Available:https://fnce.wharton.upenn.edu/wpcontent/uploads/2018/10/Quadrini_GrowthPaper-LowerCreditmsb11377.pdf Accessed on: July 8, 2019.

[15] M. Voynarenko, V. Dzhuliy, and L. Yemchuk. "Development of information systems and modeling of their implementation in the business". Problems and Perspectives in Management. International Research Journal, vol.14, no.3, pp. 102-107, 2016. Doi: http://dx.doi.org/10.21511/ppm.14(3).2016.10

[16] A. Asaul, M. Voynarenko, L. Dzhulii, L .Yemchuk, L. Skorobohata, and O. Mykoliuk, "The latest information systems in the enterprise management and trends in their development", Advanced computer information technologies (ACIT 2019) : 9th International Conference, Ceske Budejovice, Czech Republic, 2019, pp. 409-412.

[17] O. Galor, O. Moav, and D. Vollrath, "Inequality in Landownership, the Emergence of Human-Capital Promoting Institutions, and the Great Divergence", Review of Economic Studies, 2009. [Online]. Available: https://growthecon.com/assets/roes 506.pdf Accessed on: July 20, 2019.

[18] G. H. Hanson "The Rise of Middle Kingdoms: Emerging Economies in Global Trade", Journal of Economic Perspectives, 2012. [Online]. Available:https://gps.ucsd.edu/ files/faculty/hanson/hanson publicati on it kingdoms.pdf Accessed on: July 25, 2019. 